\title{
Normativas sobre el matrimonio y la residencia indígena en la Jurisdicción de Córdoba (Gobernación del Tucumán, 1573-1598)
}

(4) Lucas Borrastero*

Fecha de recepción: 12 de mayo de 2018. Fechas de aceptación: 10 de septiembre de 2018

\begin{abstract}
Resumen
En este artículo analizaremos las normativas sobre el matrimonio y la residencia indígena establecidas para la jurisdicción de Córdoba, en tanto espacio integrante de la gobernación del Tucumán, entre 1573 -año de fundación de la ciudad- y 1598, momento en el cual concluye un intercambio normativo entre el gobernador del Tucumán Pedro Mercado de Peñaloza y los vecinos de Córdoba, en torno al matrimonio y la residencia indígena. El análisis realizado busca contribuir al estudio de las características que adquirió el sistema de dominación instaurado con la encomienda de "servicios personales" y el proceso general de "hispanización" de las sociedades indígenas en la jurisdicción de Córdoba durante las primeras décadas de dominación colonial.
\end{abstract}

Regulations on marriage and indigenous residence in the jurisdiction of Córdoba (Gobernación del Tucumán, 1573-1598)

\section{Palabras clave}

normativas sobre matrimonio sociedades indígenas jurisdicción de Córdoba (Gobernación del Tucumán) hispanización

\begin{abstract}
In this paper we will analyze the regulations of marriage and indigenous residence, established for the jurisdiction of Córdoba, as a constituent part of Tucumán's Governance, between 1573 -when the city was founded- and 1598, when a normative exchange related to marriage and indigenous residence concludes between the Governor of Tucumán, Pedro Mercado de Peñaloza, and the neighbors of Córdoba. The current analysis seeks to contribute to the study of the characteristics acquired by the domination system set up by the encomienda de servicios personales (personal services) and the general process of "hispanización" (hispanization) of indigenous societies within the jurisdiction of Córdoba during the first decades of colonial domination.
\end{abstract}

Keywords

marriage regulations indigenous societies jurisdiction of Córdoba (Gobernación del Tucumán) Hispanization 


\section{Introducción}

En este artículo analizaremos las normativas sobre el matrimonio y la residencia indígena establecidas para la jurisdicción de Córdoba, en tanto espacio integrante de la gobernación del Tucumán, entre 1573 -año de fundación de la ciudad- y 1598 momento en el cual concluye un intercambio normativo entre el gobernador del Tucumán Pedro Mercado de Peñaloza y los vecinos de Córdoba en torno al matrimonio y la residencia indígena.

La primera indagación en relación a este tema fue realizada en el marco de nuestro Trabajo Final de Licenciatura (Borrastero, 2016), en el cual investigamos de manera general las formas que adquirieron las relaciones establecidas entre las sociedades indígenas y los grupos españoles en la jurisdicción de Córdoba entre 1573 y 1620. Dentro de esa investigación, y con el objetivo de conocer la gestión y los asuntos legislados por el gobernador Mercado de Peñaloza, analizamos las normativas referidas a los casamientos y a la residencia indígena registradas en las Actas Capitulares de Córdoba.

A partir de la revisión de dichas Actas (Santillán Vélez, 1880, 1882a y 1882b; Luque Colombres, 1974), ${ }^{1}$ observamos que Mercado de Peñaloza en 1595 había dispuesto para toda la gobernación del Tucumán una ordenanza sobre el matrimonio y la residencia que modificaba una serie de legislaciones previas realizadas por el gobernador Gonzalo de Abreu -en 1579-, específicamente para Córdoba. Estas últimas instituían un sistema de residencia "patrilocal" para los casamientos indígenas, que sería luego modificado por Mercado de Peñaloza quien reglamentaría un novedoso sistema "matrilocal". ${ }^{2}$ Esta última ordenanza sería sin embargo rechazada por los vecinos de Córdoba, quienes buscarían que el nuevo sistema "matrilocal" se aplicara sólo en el espacio urbano y que en el espacio rural continuara el anterior sistema "patrilocal". En el marco de nuestro Trabajo de Licenciatura, el análisis de este fenómeno nos permitió realizar una primera aproximación al proceso de "hispanización" divergente, existente entre los grupos encomendados que trabajan en el espacio urbano y rural de la jurisdicción de Córdoba.

Recuperando estos avances previos, en este artículo profundizaremos nuestra indagación en torno a las legislaciones sobre el matrimonio y la residencia indígena, entendiendo a las mismas como partes del sistema de explotación configurado con la encomienda de "servicios personales" y el proceso general de "hispanización" de los grupos indígenas en la jurisdicción de Córdoba, durante el periodo colonial temprano.

En la primera parte de este trabajo revisaremos el contexto normativo general, previo a las ordenanzas de Abreu de 1576, indagando en los aspectos más relevantes del sistema de explotación de la población nativa establecido por Virrey Francisco de Toledo durante la década de 1570 para la zona central andina y las disposiciones religiosas instituidas por el Tercer Concilio Límense (1582-1583). El contexto normativo previo nos permitirá observar las principales transformaciones llevadas a cabo sobre la forma de vida de grupos indígenas pertenecientes al espacio andino y las diferencias existentes respecto del dominio colonial configurado en la gobernación del Tucumán, región marginal dentro del virreinato del Perú.

A partir de lo anterior, describiremos las principales características del sistema de encomienda de "servicios personales", "legalizado" en el Tucumán con las ordenanzas de Abreu de 1576; para luego recuperar -sintéticamente- nuestro 
examen previo sobre las formas que adquirieron las relaciones establecidas entre los grupos nativos y españoles en Córdoba.

En la segunda parte, examinaremos las normativas instituidas en 1579 por Abreu para la jurisdicción analizada, que reglamentaron un sistema "patrilocal" para los matrimonios, y la modificación posterior realizada por Mercado de Peñaloza en 1595. Este último, establecería una nueva regla "matrilocal" para la gobernación, generando el inmediato rechazo por parte de los vecinos de Córdoba, quienes buscarían introducir un sistema "divergente" para los casamientos indígenas del espacio urbano y rural de su jurisdicción. Paralelamente revisaremos las disposiciones relativas al matrimonio y la residencia, instituidas en el Primer Sínodo del Tucumán (1597) donde este asunto fue abordado específicamente, para conocer algunas características del fenómeno no mencionadas en otros documentos.

Finalmente, explicaremos cómo continuó -y consideramos concluyó- el intercambio normativo entre Mercado de Peñaloza y los cabildantes de Córdoba en 1598 -año en el que las Actas Capitulares consultadas contienen el último registro sobre el tema- y reflexionaremos sobre el proceso de "hispanización" de los grupos locales sometidos al sistema de encomiendas de "servicios personales" en Córdoba.

\section{Primera Parte}

Para comenzar nuestro análisis consideramos necesario aclarar dos aspectos vinculados a la documentación analizada. En primer lugar, al examinar las normativas sobre el casamiento y la residencia indígena, observamos la existencia de dos tipos de legislaciones que reglamentaban este asunto: las provenientes de las autoridades civiles -Órdenes Reales, Ordenanzas de Gobernadores, Mandamientos, Autos, etc.- y las emanadas de las autoridades eclesiásticas -realizadas en el marco de los Concilios Provinciales, Sínodos Diocesanos, etc. Si bien reglamentar sobre la forma que debía tener el sacramento del matrimonio y la consecuente vida conyugal, tanto para los españoles como para los indios, era un asunto que concernía de manera específica a las autoridades de la iglesia, dentro del espacio colonial las autoridades civiles también legislaron sobre esta materia en virtud del Patronato Real establecido desde las bulas papales emitidas por Alejandro VI a los Reyes Católicos. Esta concesión les había permitido a funcionarios del Estado Colonial legislar sobre asuntos religiosos y temas relacionados a la evangelización (Arancibia, 1972: 94; Crouzeilles, 2007: 15-21).

Luego de reparar en la distinta procedencia de las normativas analizadas, en segundo lugar observamos que cuando las autoridades españolas -sobre todo las civiles- legislaron sobre los "matrimonios", no solo estaban reglamentando la forma religiosa que debían tener las uniones conyugales indígenas sino que también buscaban definir el tipo de unidades tributarias / familiares que debían tener los indígenas; y al reglamentar sobre la "residencia", más que una preocupación por definir el modo de habitar indígena observamos la intensión por fijar un lugar de tributación y/o servicio para los grupos sometidos al dominio colonial.

Teniendo en cuenta lo anterior, a lo largo de este trabajo complementamos la información contenida en la Actas Capitulares con el examen de las regulaciones provenientes tanto de las autoridades civiles -Ordenanzas de Toledo 
1570, de Abreu 1576, etc.- como de las autoridades religiosas -Tercer Concilio Límense 1582-83, Primer Sínodo del Tucumán 1597, etc.- y otros documentos, considerando en cada uno de ellos el significado o valor que pudieron adquirir los términos "matrimonio" y "residencia" indígena.

\section{El contexto normativo previo a las Ordenanzas de Abreu}

Para comprender el significado de las ordenanzas establecidas por el gobernador Abreu (1576), que fueron el marco regulatorio de la encomienda de "servicios personales" en el Tucumán, consideramos necesario conocer las normativas que regulaban de manera general la explotación de la población indígena en la zona central del virreinato del Perú, centrándonos especialmente en las reglas referidas al casamiento y a la residencia.

Según la síntesis elaborada por S. Palomeque (2000), el Virrey Toledo luego de realizar, durante la década del 1570, una "Visita General" a las poblaciones nativas de los actuales países de Ecuador, Perú y Bolivia, consolidaría un sistema de explotación que, si bien tenía la apariencia de continuidad con el incario, modificaría sustancialmente el orden anterior, sometiendo a las sociedades nativas a múltiples cambios económicos, religiosos, políticos y culturales.

De manera general, este sistema estableció un plan masivo de "reducciones", la organización del sistema de autoridades políticas y la creación de la "república de los indios" separada de la de los españoles. Las "reducciones" fueron el eje de todo el sistema de control al que sería sometida la población indígena, implicando una gran transformación en las formas de asentamiento, de gobierno y de vida dentro del mundo andino. Esta política consistió en "numerar" los tributarios y sus familias, "asentarlos" a todos, prohibir su desplazamiento y darles "policía y doctrina".

La población asentada quedaba obligada al pago de un tributo diferencial según el grupo o el pueblo, en su mayor parte fijado en dinero, que debía ser obtenido trabajando de manera rotativa principalmente en las minas u otras empresas de españoles. Este trabajo se pagaba según un salario normado por la autoridad colonial, reglamentándose también la cantidad de indios destinados a cada empresa española, sistema al que se le daría el nombre de "mita". El funcionario visitador fijó el tributo o la tasa que debían pagar los indios,

3. Aunque la política establecida por el Virrey Toledo fue mucho más compleja, reglamentando no solo la situación de los indígenas asentados en pueblo de reducción -que pasarían a denominarse "originarios"- sino también la de los "yanaconas" y "forasteros" -cada uno de los cuales tendría un régimen particular-, aquí solo señalamos los elementos generales de este sistema para poder contextualizar el tema analizado.

4. Con la implantación de su sistema político más varias medidas contrarias a las sociedades nativas el Virrey Toledo lograría desarmar el proyecto colonial alternativo denominado por C. S. Assadourian (1994) como "partido de los indios", integrado por religiosos lascasianos, funcionarios de la corona y los grandes señores étnicos. calculándola de acuerdo con el número de "tributarios" -hombres aptos de 18 a 50 años-, y estipulando la "mita"; es decir, el porcentaje rotativo de dichos tributarios que debía salir de sus tierras a trabajar, a qué lugar de la economía española debería ir y a cambio de qué salario (Palomeque, 2000: 111-112). ${ }^{3}$

Con el establecimiento de este sistema de explotación en el Perú, se pondría fin al proyecto señorial defendido por los grupos encomenderos, cortando la relación directa entre estos últimos y los indios encomendados, que comenzarían a pagar su tributo a los funcionarios de la Real Hacienda y no al encomendero; sumado a esto, dicho tributo ya no sería medido en "trabajo" sino con una "tasa" en dinero estipulada como renta anual, liberando así al indio de la sujeción personal directa. ${ }^{4}$ Con las Reformas de Toledo, se estableció también una organización tributaria centrada en la figura de los varones -aptos, de 18 a 50 años-, fijando un patrón de residencia "patrilocal" para la familia indígena, como puede observarse en las Ordenanzas Generales para la vida común en los pueblos de indios realizadas por Toledo en 1575, más específicamente en la Ordenanza I (Titulo IX) denominada: Que los hijos sigan y reconozcan el ayllu o 
parcialidad de sus padres y no el de la madre, en la cual se legislaba que los indios casados y sus hijos debían tener como lugar de residencia el repartimiento, parcialidad y ayllu en el que tributaba el esposo/padre del matrimonio. ${ }^{5}$

Este nuevo orden, instituido para las familias nativas de la zona central andina por las autoridades civiles, sería también regulado por el Clero secular de la iglesia en el marco de los primeros Concilios celebrados en Lima durante el periodo analizado. El Tercer Concilio Límense realizado en 1582-83 fue el más importante de las primeras reuniones religiosas en el virreinato del Perú, por la relevancia de sus legislaciones -que retomaron las disposiciones del Segundo Concilio Límenes de 1566-1568-, por su influencia posterior y por ser el único cuyas acciones serían aprobadas y confirmadas por el Rey de España.

La disposiciones elaboradas en Lima siguieron los lineamientos generales instituidos por el Concilio de Trento (1545-1563), donde se revisaron y transformaron las principales pautas eclesiásticas, adquiriendo el Clero y el Estado un rol central como poderes garantes de las nuevas normativas; Felipe II no sólo respaldaría esta reforma religiosa sino que la convertiría en ley hacia $1564 .^{6}$

Uno de los temas nodales discutidos y regulados en Trento fue la institución del matrimonio, sacramento que sería detalladamente codificado y que pasaría a ser jurisdicción exclusiva de la iglesia, aunque -como ya mencionamos- en las colonias esta última sería compartida con el Estado en virtud del Patronato Real. En este Concilio, la iglesia otorgó al matrimonio una forma legal y religiosa, lo que le permitió avanzar sobre el control de las familias y la sociedad en general (Latasa, 2005: 237-239). ${ }^{7}$

En el virreinato del Perú, la normativa de Trento sobre los casamientos fue incorporada rápidamente a los Concilios Provinciales de Lima, Arquidiócesis a la que pertenecía el Tucumán como veremos más adelante. A partir de la década de 1580, los cambios instituidos por la iglesia también estuvieron estrechamente vinculados a los del Estado en el espacio andino; por ejemplo, con la política de "reducciones" este último buscó no sólo organizar el tributo colonial sino también establecer un espacio de control para la evangelización de las poblaciones nativas (Imolesi, 2012: 89).

Durante el Tercer Concilio se realizaron varias disposiciones relacionadas con la libertad de los indios para contraer matrimonio y con la forma que debían tener los mismos; la iglesia, al igual que las ordenanzas de Toledo, penalizó por ejemplo el servinakui -que era en términos generales la costumbre que tenían los grupos nativos de convivir o tener relaciones pre-maritales-, 8 estableciendo que los matrimonios indígenas residieran juntos sólo después de haber contraído el sacramento y fijando la residencia del matrimonio indígena en el lugar donde residía y/o tributaba el esposo/padre (Imolesi, 2012: 90-97).

Si bien con esta breve síntesis no pretendemos explicar las complejas transformaciones establecidas con las reformas realizadas por el Virrey Toledo y por el Tercer Concilio Límense, buscamos señalar las características más relevantes que adquirieron las formas de explotación de las sociedades indígenas en el espacio andino, centrándonos en las legislaciones realizadas en torno al casamiento y la residencia. En relación a este último asunto, observamos cómo la Corona logró en la zona central del virreinato recortar el proyecto señorial encomendero e imponer una forma de organización de los grupos nativos, que implicó -entre otros asuntos- un ordenamiento tributario y matrimonial de tipo "patrilocal" para las familias sometidas al dominio colonial. La búsqueda por
5. En esta normativa se ordenaba que "la india de un repartimiento, parcialidad y ayllu que se casare con indio de otro, deje los hijos que en ella hubiere habido su marido, en el repartimiento, parcialidad y ayllu donde su padre era tributario, porque alli lo han de ser ellos". A su vez, en 1575 el Virrey Toledo estableció otra legislación con el mismo objetivo, contenida dentro de las Ordenanzas particulares para los pueblos de indios del distrito de la Paz (Sarabia Viejo, 1989: 213 y 255).

6. Felipe II ordenó la realización de una Junta Magna en 1568, de la cual saldrían detalladas instrucciones para ordenar la vida de los territorios americanos. De esta reunión resultó una amplia recopilación legislativa que influyó notablemente en la función que pasarían a tener las colonias americanas para la metrópoli. Además La Junta Magna reguló sobre diversos asuntos eclesiásticos, entre ellos la instauración del Santo Oficio de la Inquisición en América, medida que estaba destinada a garantizar la ortodoxia religiosa en el continente americano (López Lamerain, 2011: 57-58).

7. En el Concilio de Trento al reglamentarse el matrimonio se exigía para su validez: la publicidad de las amonestaciones, la recogida de informaciones, la celebración de los esponsales ante un sacerdote o párroco, la presencia de testigos y el registro escrito. El Decreto Tametsi de 1563 , además de asentar la necesidad del libre consentimiento de las partes, reguló canónicamente el matrimonio católico, representando una solución de compromiso ante el grave problema de los casamientos clandestinos -declarados nulos a partir del Concilio de Trento- y el remedio de dar la mayor publicidad posible a los enlaces (Latasa, 2005: 243-251). La bibliografía sobre el Concilio de Trento, en general, y sobre las regulaciones del matrimonio, en particular, es extensa y en la misma se describe con detalle las transformaciones religiosas y sociales realizadas. Para profundizar sobre este tema se puede consultar a Rípodas Ardanaz (1977), Arellano y Usuñariz (2005) e Imolesi (2012), entre otros.

8.En este trabajo no analizaremos las diversas características que tuvieron las uniones y las formas de parentesco de los distintos grupos que habitaron el espacio andino durante el periodo anterior a la conquista española, tema que excede ampliamente los objetivos propuesto en el presente análisis y sobre el cual se pueden consultar los artículos compilados por Mayer y Bolton (1980) y por Arnold (1998). 
9. Según Assadourian (1972), el proceso de conquista del sur del virreinato del Perú se inició como parte de otro proceso de "descarga de la tierra" y de expansión de la frontera impulsado por la Corona española. Esta buscaba, por un lado, resarcir a través de mercedes en nuevos territorios -como Chile y el Tucumán- a los colaboradores en las "guerras civiles" entre pizarristas y almagristas primero, y a los que participaron en el aplastamiento de la "sublevación de los encomenderos" desarrollado entre 1540 y 1550 después. y, por el otro, la Corona deseaba empujar las fronteras para incorporar nuevos espacios. En este contexto, se daría la conquista y posterior conformación de las Gobernaciones de Chile y de Tucumán que, cada una con sus particularidades, formaron parte de una "conquista privada" que fortaleció a los grupos privados encomenderos que lograrían mantener -por un largo tiempo- a las poblaciones nativas bajo el sistema de explotación de la encomienda de "servicio personal". Para profundizar sobre las características específicas de este proceso en la gobernación de Chile ver Álvaro Jara (1981), entre otros.

10. Aunque las ordenanzas de Abreu establecieron como tributarios para la mita sólo a los varones indígenas -de 15 a 50 años-, reglamentaban las ocupaciones de toda la familia: Niños -menores de 10 años-; Muchachos -10-15 años-; Indias -10-50 años-; Viejos -50-70 años-; Viejas -50-55 años- e incluso de viudas y huérfanos. (Levillier, 1920b). aplicar estas reformas, por parte de las autoridades del Tucumán, ocasionaría importantes conflictos con los grupos encomenderos, según iremos mostrando a lo largo del artículo.

\section{Las Ordenanzas de Abreu de 1576}

Los cambios establecidos por Toledo en las formas de explotación y de organización de los indios en el espacio andino no se aplicarían rigurosamente en las zonas marginales del virreinato del Perú, como las gobernaciones del Tucumán y de Chile, que soportarían un largo proceso de conquista, donde las huestes -luego devenidas en vecinos encomenderos- adquirían un gran poder a medida que sometían a las poblaciones que habitaban estos espacios.

El proceso de conquista llevado a cabo por las huestes en estos espacios fue denominado por C. S. Assadourian como "conquista privada" y consistió en el vínculo establecido entre la Corona española y los conquistadores, mediante el cual la primera buscó imponer "la totalidad de las cargas económicas de la expedición a la iniciativa privada, que acepta un convenio de esta naturaleza animada por la esperanza de resarcirse, de inmediato y con exceso, de los desembolsos realizados" (Assadourian, 1972: 23). La principal recompensa otorgada por la Corona en lugares como la gobernación del Tucumán o la de Chile fue la merced de encomienda, que se convirtió en la institución vertebradora de la explotación de la fuerza de trabajo indígena, garantizando su monopolio. El régimen de encomienda establecido en estos espacios se caracterizó por la continuidad del "servicio personal", llegando en el Tucumán incluso hasta fines del siglo XVIII. ${ }^{9}$

Este periodo fue descripto tempranamente por A. M. Lorandi, quien evidenció las particularidades del Tucumán en tanto espacio marginal del virreinato o sociedad de frontera, en donde los controles institucionales resultaron poco efectivos y las desviaciones respecto a las normativas reales fueron mucho mayores que en las zonas centrales, quedando la región bajo la tutela de un gobernador y los indios repartidos en encomiendas privadas -con pocas excepciones- (Lorandi, 1988: 140).

El sistema de tributación establecido con la encomienda de "servicios personales" fue "legalizado" con las ordenanzas de Abreu de 1576, realizadas para la mesopotamia santiagueña y luego extendidas hacia el resto del Tucumán. Éstas no fijaron una "tasa" en producto o dinero, tampoco consideraron como tributario al varón entre 18 y 50 años, ${ }^{10}$ ni separaron al pueblo de indios del encomendero, como en el resto del virreinato. Por el contrario, autorizaron a los encomenderos a mantener a los indios como sus vasallos; es decir, a mantener "sujeta bajo su jurisdicción" a toda la familia indígena, sobre la cual ejercieron su dominio sin ningún control estatal. Desde una perspectiva institucional, el sistema de encomienda fue mixto en tanto continuaron vigentes los "servicios personales" de los indios propios de la encomienda peruana previa a $1545 \mathrm{y}$, paralelamente, se reguló su duración y el tipo de trabajo a través de una normativa estatal propia del período toledano (Palomeque, 2000: 114-115).

El sistema de explotación "legalizado" por Abreu consistió en la primera injerencia estatal en el Tucumán, en la que -sin embargo- se incluyeron escasas modificaciones al régimen de explotación ya vigente en la práctica. En esta gobernación, las decisiones de las autoridades coloniales fueron flexibles frente 
a los vecinos-encomenderos, autorizándolos a mantener formas de explotación directa sobre los grupos encomendados. Según afirma Doucet, Abreu "acordó" las primeras ordenanzas, en tanto no pudo imponer el cumplimiento de otras normativas que había dictado anteriormente debido a la resistencia de los encomenderos, siendo así las legislaciones que conocemos el fruto de un acuerdo entre ambas partes (Doucet, 1990: 149-150).

Varios elementos influyeron para que estas normativas fueran muy diferentes a las toledanas; por un lado, se dictaron cuando aún no se concluía la conquista del Tucumán, donde era indispensable la participación militar de los encomenderos; por el otro, el funcionario estatal que dictó las legislaciones era un encomendero y, a su vez, en esta gobernación no existieron -como en otros espacios- los grupos que habitualmente peleaban por debilitar el poder de los encomenderos; entre ellos, los sectores religiosos, los grandes señores étnicos o los empresarios españoles que no tenían encomiendas y necesitaban trabajadores (Palomeque, 2000: 112). Así, la falta de control de los funcionarios, la ausencia de grupos con poder que se opusieran al sector encomendero y el fuerte peso de la institución de la encomienda llevó al incremento de los grados de explotación a las sociedades nativas, lo que sumado a lo anterior generó un gran descenso demográfico en los primeros años coloniales y llevó a que las autoridades siempre debieran negociar con el poder privado para poder implementar las políticas de la Corona.

Según entendemos, este es el contexto general en que deben entenderse las ordenanzas de Abreu de 1576 y las de 1579, específicas para la jurisdicción de Córdoba. Si bien estas últimas fueron normativas de menor alcance, incorporaron reglas específicas sobre el matrimonio y la residencia indígena.

\section{Las sociedades indígenas y los grupos españoles en la jurisdicción de Córdoba}

Antes de profundizar el análisis de las normativas aquí analizadas consideramos pertinente recuperar sintéticamente las formas que adquirieron las relaciones establecidas entre las sociedades indígenas y los grupos españoles en la jurisdicción de Córdoba durante el periodo colonial temprano, para comprender mejor la especificidad del fenómeno examinado.

En nuestro trabajo previo (Borrastero, 2016) indagamos en las diversas características que adquirió la participación de la población nativa en las actividades mercantiles urbanas y rurales organizadas por los colonos españoles, centrando nuestro examen en el espacio urbano a partir la revisión detallada de una visita realizada al servicio de indios urbanos en 1598 por órdenes de Mercado de Peñaloza (Piana, 1987).

Allí, observamos cómo hacia fines del siglo XVI los vecinos encomenderos de Córdoba lograron generar una producción local diversificada, gracias al paulatino sometimiento de los grupos nativos, que les permitirían insertarse en amplias redes comerciales promovidas por el mercado dominante en Potosí. La producción diversificada organizada por los vecinos se iría especializando hacia fines del siglo XVI en la producción textil, la cual comenzaría como una actividad doméstica urbana y trabajo no especializado en pueblos de encomienda, para luego especializarse con la instalación de obrajes en el espacio rural (Assadourian, 1982; Doucet, 1986). 
11. Sobre la producción textil y los oficios realizados por los grupos indígenas en las unidades productivas de la jurisdicción de Córdoba -entre 1573 y 1620 - se puede consultar un artículo específico (Borrastero, 2015).

12. Al respecto, Piana examinó de forma pormenorizada los fletes o trajines procedentes de Córdoba, basándose en los registros que debían hacer los encomenderos cuando sacaban indios. A partir de estos últimos la autora evidencia la activa participación de los vecinos de Córdoba en los circuitos comerciales existentes entre Buenos Aires y Potosí y secundariamente con la zona de Cuyo (Chile), entre los años 1580 y 1610 (Piana, 1992: 197-206).

13. La saca y movimiento de la población nativa llevada a cabo por los encomenderos y comerciantes fue un fenómeno muy difundido dentro la gobernación del Tucumán, en general, y en la jurisdicción de Córdoba, en particular. El mismo buscó ser regulado por muchas autoridades durante el periodo colonial temprano, como puede observarse en un mandamiento de Mercado de Peñaloza en 1597, que afirmaba: "cuando llego su señoria al govierno destas provincias hallo que los vezinos de la dicha ciudad de Córdoba estavan en costumbre de embiar carretas y servicio de yndios al puerto de buenos ayres y traer fletados esclabos a esta ciudad y al presente se an querido y quieren estender mas adelante hasta la ciudad de salta y jujuy camino de mas de quatrocientas leguas y si se diese lugar a ello seria y es en gran daño y prejuyzio de los naturales" (Santillán Vélez, 1882b: 48). Otras numerosas referencias sobre este proceso pueden consultarse en Levillier (1920a).

14. La Ord. 22 describe: "la ocasión que tienen los naturales de [...] hazer otros daños cassandose oy en un pueblo y mañana en otro es dejallo andar bagamundos de pueblo en pueblo y consentirlos en ellos los encomenderos"; de donde podemos inferir que los indígenas realizaban más de un casamiento -en diferentes pueblos- y que esto era permitido por los encomenderos. (continúa en página 47 ).

15. Aunque las ordenanzas establecidas en 1579 por Abreu para la (continúa en página 47).
A partir del análisis de la visita, analizamos los oficios que estaban a cargo de familias indígenas que habían sido trasladas hacia el espacio urbano principalmente desde el noroeste de la jurisdicción de Córdoba. Este espacio, según las investigaciones etnohistóricas y arqueológicas consultadas (Piana, 1992; Castro Olañeta, 2006; Laguens y Bonnin, 2009; Carmignani, 2013, entre otros), había estado habitado durante el periodo prehispánico tardío por poblaciones que, si bien no eran homogéneas, compartían algunos rasgos generales como: vivir en aldeas agrícolas ubicadas principalmente en los fondos de valle o en lugares cercanos a las aguadas, espacios de residencia que articulaban con la utilización de otros ambientes dispersos donde realizaban actividades de caza y recolección. A su vez, el registro arqueológico permite pensar en la presencia de habilidades textiles que les habría permitido a estos grupos, al menos, tejer redes y lanas con las que habrían hecho sus vestimentas o bolsas para el traslado de alimentos.

Luego de clasificar y analizar los oficios registrados en la mencionada visita destacamos la importancia de los trabajos vinculados a la producción textil, realizados por las mujeres indias dentro de las "casas" de los encomenderos, bajo la supervisión de las esposas de estos últimos. Esta producción, a diferencia de los textiles "bastos" elaborados en los pueblos de encomienda y en los obrajes, era de finos "acabados" de piezas textiles. ${ }^{11}$ En relación a los oficios masculinos registrados, observamos que los encomenderos utilizaban a los hombres en trajines y arreos -actividades previamente analizadas por Piana (1992)- ${ }^{12}$, además del cultivo de las chacras cercanas a la ciudad, tareas también muy valoradas en el espacio urbano.

Según planteamos en nuestra investigación, los oficios femeninos y masculinos realizados en las unidades productivas urbanas se diferenciaban por la alta valoración que los encomenderos otorgaron a las actividades textiles llevadas a cabo por las mujeres indias; en comparación con el gran nivel de movilidad existente entre los trabajadores masculinos, sobre los cuales hay numerosas referencias documentales que evidencian cómo eran utilizados en trajines y arreos de los cuales muchas veces no volvían -siendo incluso vendidos en lejanas tierras. ${ }^{13}$

Las distintas especializaciones laborales -oficios- desarrolladas por las mujeres y varones indígenas en las áreas productivas del espacio urbano y rural, sería uno de los principales argumentos expuestos por los miembros del cabildo de Córdoba ante Mercado de Peñaloza, al requerirle que modifique la normativa sobre los matrimonios y la residencia, como veremos a continuación.

\section{Segunda Parte}

\section{Ordenanzas sobre el matrimonio y la residencia indígena (Abreu 1579 y Mercado de Peñaloza 1595)}

Aunque las normativas realizadas por Abreu en 1576 no se refirieron específicamente al casamiento y la residencia de las poblaciones nativas -sólo hay dos ordenanzas que mencionan indirectamente este tema- ${ }^{14}$ en 1579 dicho gobernador estableció una serie de legislaciones para Córdoba, más limitadas en el alcance y la proyección pero más concretas en relación al fenómeno analizado y que no han sido trabajadas específicamente por las investigaciones previas. ${ }^{15}$ 
Para analizar estas legislaciones recuperamos la metodología propuesta por Doucet en su investigación sobre las ordenanzas de Abreu de 1576, donde el autor plantea que las ordenanzas estudiadas aportan valiosa información sobre los asuntos puntuales que buscaban legislar y que, a su vez, las mismas constituyen "testimonios" del real funcionamiento de las encomiendas, en el momento previo y contemporáneo al que fueron realizadas (Doucet, 1990: 159-160). Partiendo de este enfoque, consideramos que el análisis de las tensiones entre diferentes actores y las contradicciones evidenciadas en la documentación normativa aquí presentada nos permitirá aproximarnos -al menos indirectamente- a lo que podía estar sucediendo en relación a los matrimonios y la residencia indígena en la práctica.

A partir de la revisión de las Actas Capitulares, observamos que la "Ordenança açerca de los naturales de esta çiudad" fue establecida por Abreu en 1579 con la finalidad de legislar sobre distintos asuntos referidos a los habitantes -españoles e indígenas- de esta ciudad. De las diez normativas instituidas, las ordenanzas 1, 2, 3 y 4 reglamentaron el accionar y las prioridades que se debían tener en los pleitos por encomiendas, instituyendo que se privilegiara la posesión de los primeros encomenderos por sobre los beneficiarios posteriores y los que tuvieran bajo su poder pueblos, asientos o caciques sin haberlos recibido en encomienda. Las ordenanzas 5, 6, 7 y 10, como veremos, regularon el matrimonio y la residencia de los grupos encomendados. La Ord. 8 trata sobre el lugar donde debían "naturalizarse" los indios y sobre el traslado o saca de indios -desde sus lugares de origen- por parte de los encomenderos. Finalmente, la Ord. 9 no es muy clara y se refiriere al orden que debía existir entre las parcialidades y los caciques dentro de una encomienda (Luque Colombres, 1974: 298-301).

Aquí nos detendremos en la indagación de las ordenanzas 5, 6, 7 y 10 (Luque Colombres, 1974: 298-301) que establecieron reglas sobre la residencia de los indígenas luego de casarse, y sobre las distintas posibilidades existentes en relación a este asunto. A manera de ejemplo, citaremos la Ord. 6 y la Ord. 10. La Ord. 6 reglamentaba que:

Yten, es orden, si el yndio de un pueblo se casaçe con yndias de otro, todos los hijos e hijas que durante el matrimonio pariere la dicha yndia, se entienda ser naturales del pueblo que fuere natural el yndio marido de la dicha yndia y si pariere despues de muerto el marido, sea del pueblo del padre e de la madre y siendo de otro donde naçiere la criatura despues de aber muerto el padre, sea del que dentro de tres años quisiere bibir la madre del pueblo suyo o de su marido y si dentro de tres años de como murio el marido [Testado: bi] no bibiere en su pueblo ni en el de su marido, sea la criatura del pueblo del marido de la dicha yndia, como se entienda ser avido la dicha criatura durante el matrimonio de los yndios que se averiguaren(Luque Colombres, 1974: 299). ${ }^{16}$

Con esta normativa se legislaba que los hijos que tuvieren los indígenas casados, pertenecientes a distintos pueblos, deberían residir en el pueblo -de encomienda- del esposo/padre, a no ser los nacidos después que este hubiese muerto. A su vez, la Ord. 10 establecía que:

Yten, el orden que los yndios que se ovieren cassado con una muger y no con mas en su ley antes que entrasen los españoles en estas Provincias a poblar, sean validas y que las mugeres vayan con sus primeros maridos porque suelen cassarse segunda vez y dexan los maridos y que desde oy en adelante no sea
16. Tanto en esta cita documental como en las próximas, los subrayados y las anotaciones entre corchetes son nuestras. 
valido el casamiento en su lei ni pase ni conpra ni benta que hazen de mujeres (Luque Colombres, 1974: 299).

Esta ordenanza buscaba regular el casamiento de las poblaciones nativas a partir de la entrada de los españoles, estableciendo el pueblo del hombre -y su encomendero- como lugar de residencia del matrimonio indígena según un nuevo sistema. A su vez, se prohibían situaciones prehispánicas como los casamientos femeninos sucesivos. En la última parte la normativa se ordenaba que no hubiera "ni pase ni conpra ni benta que hazen de mugeres", lo que probablemente se refiriera a una situación, propia del periodo colonial, alusiva a la compra y venta o pase de personal de servicio femenino entre los encomenderos de la ciudad.

De manera general, podemos sintetizar que con las legislaciones instauradas en 1579 por Abreu se instituía para Córdoba un sistema de residencia "patrilocal" para los casamientos indígenas en donde, a no ser luego de la muerte de marido, el matrimonio y sus hijos debían residir -y servir- en el pueblo -de encomienda- del esposo/padre. En este sentido, entendemos que estas reglas seguían los lineamientos establecidos por Toledo y por el Tercer Concilio Límense para el área central andina.

Posteriormente, Mercado de Peñaloza instituyó en mayo de 1595 una serie de mandamientos para toda la gobernación que revocaba lo regulado por Abreu en 1579 para Córdoba. En 1594 realizó un mandamiento en Santiago del Estero, con traslado a Córdoba en 1595, en el que se ordenaba:

[...] por quanto debe guardarse en esta ciudad e provincia la ordenanza ffecha por gonzalo de abrego governador que fue en ella por la qual ordenó y mandó que las yndias de vezinos que se casasen con indios de vezinos encomenderos sirviesen al encomendero y señor de tal indio rresultan gravisimos daños e incovenientes como son que aviendo criado los señores de tales dichas indias a muchas dellas en sus casas mostrandoles e industriandolas en mucha limpiesa e pulicia e que sepan coser y labrar guisar de comer y hazer otros oficios en lo qual gastan mucho tiempo e trabajo casandose con indio vecino se lleva

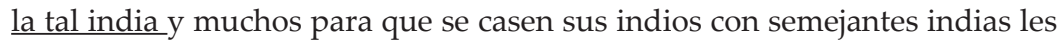
yncitan y animan a que las inquieten y saquen de casa de sus amos [...] y $\underline{\text { lo }}$ que peor es es que los dueños de las dichas indias por prevenirse deste daño casan las dichas indias muy muchachas e niñas de menor de edad de lo que manda el derecho con indios muchachos e niñas de muy poca edad muchas vezes por fuerza e contra su boluntad y sin entender ni aver entender la fuerza del sacramento del matrimonio que contraen [...] por todo lo qual rrebocava e rreboco la dicha ordenanza e ordenava e mandava y ordeno y mando que de oy en adelante para sienpre jamas o hasta tanto que su magestad provea y mande otra cosa los tales indios de vecinos asi desta ciudad como de todas las demas ciudades villas y lugares desta provincia que se casazen con qualesquier indias de vezinas asi de las que tubiere criadas en sus casas como en sus pueblos sirvan al encomendero y señor de la dicha india luego que se casaren con lo qual cesaran tantos y tan graves incombinientes (Santillán Vélez, 1882a: 409-410).

En este mandamiento pueden observarse dos fenómenos importantes: en primer lugar y principalmente, anulaba la ordenanza establecida por Abreu en relación a la residencia "patrilocal" de los indios casados. Mercado de Peñaloza, con el objetivo de que cesaran "tantos y tan graves incombinientes" entre los vecinos encomenderos, reglamentó que los hombres indígenas que 
se casaren debían trasladar su residencia al pueblo y/o a la "casa" de la encomienda de sus mujeres; es decir, instituía un novedoso sistema "matrilocal" donde quedaba explícito que las mujeres indígenas eran muy valoradas por los encomenderos, que habían realizado una gran inversión en su educación e "hispanización". Según entendemos, este cambio obedece a que Mercado de Peñaloza comprendía el alto valor que para determinados encomenderos tenían las mujeres dentro del Tucumán e implementa así un sistema de residencia para los matrimonios contrario al que se venía estableciendo de forma general para el virreinato del Perú.

En segundo lugar, el mandamiento nos muestra una de las estrategias utilizadas por los vecinos españoles para evitar el "robo" de sus valiosas mujeres de servicio, que era casarlas "muy muchachas y niñas" por la "fuerza y contra su voluntad" asegurándose tempranamente el control del cónyugue y su consecuente residencia. La realización de matrimonios forzados sería también denunciada por las autoridades religiosas en el marco del Primer Sínodo del Tucumán de 1597, como observaremos más adelante.

Luego de ser pregonado el mandamiento de Mercado de Peñaloza en agosto de 1595, los vecinos de Córdoba representados en el cabildo mandaron a pedir al gobernador que dicha ordenanza corriera sólo sobre las indias de las "casas", y no sobre las de los "pueblos":

[...] no hera questo [lo establecido por el mandamiento] se entendiera en estos pueblos sino tan solamente con las yndias y servicio de cassa atento a todo lo qual suplicavan a su señoria enbie nueba declaracion aserca destos casamyentos en los pueblos y que en el entretanto suplicavan [que no se cumpliera] el dicho mandamiento en quanto a los casamyentos en estos pueblos de los encomenderos (Santillán Vélez, 1882a: 411).

Este fragmento nos muestra, en primer lugar, la diferencia que existía para los encomenderos entre los oficios llevados a cabo por los indígenas de las "casas" de la ciudad y los trabajos de los que estaban en los "pueblos" rurales, cobrando en la ciudad más importancia o valor el trabajo femenino, mientras en los "pueblos" -rurales- parecía suceder lo contrario pues se valoraba más el trabajo masculino, el cual quizás tuviera una movilidad menor en relación al realizado por sus pares en el espacio urbano. Esto nos permite pensar en la existencia de lógicas de vinculación divergentes entre los grupos españoles e indígenas dentro de un espacio y de otro.

Dicha petición sería reiterada por los vecinos de esta ciudad un año después -en 1596- en una Instrucción enviada a Mercado de Peñaloza, en la cual los cabildantes insistían en:

[...] pedir a su señoria del señor governador aga merced a esta ciudad de declarar sobre los casamyentos de los naturales desta provincia [que] en los rrepartimyentos de indios se guarde el uso y costumbre $[\ldots]$ y en lo demás se guarde la orden que su señoria tiene mandado por su ordenanza en los camientos [casamientos] del servicio y personas de la ciudad porques en pro della y se rrecibe mucha quietud porque an sesado muchas pesadumbres que solian rrecrecer entre los vezinos (Santillán Vélez, 1882a: 426-427).

En esta Instrucción los cabildantes pedían al gobernador que en "los repartimientos de indios" -espacio rural- se mantuviera el "uso y costumbre"; es decir, la regla "patrilocal" -establecida previamente por Abreu-, mientras que para 
17. En la petición o recaudo a la ordenanza de Mercado de Peñaloza de 1595 de 05/08/1595, de los nueve vecinos firmantes -incluyendo al escribano- tres de ellos -es decir, el 33\%- aparecen como Alcaldes de la Santa Hermandad: Alonso de la Cámara, Juan de Ludeña y Rafael Antonio de Palencia, a pesar de que como máximo debía haber dos por sesión. Mientras que en la Instrucción realizada el 20/04/1596 en la cual se repetía el pedido de modificación del mandamiento sobre la "matrilocalidad", de los seis cabildantes que firman, dos -es decir, el 33\%- eran Alcaldes de la Santa Hermandad: Juan de Barrientos y Juan Nieto (Santillán Vélez, 188za: 408-410 y 424-427). Esta proporción de Alcaldes de la Santa Hermandad en las sesiones del cabildo no era lo común durante el periodo analizado.

18. En un primer momento estos funcionarios fueron nombrados por los gobernadores pero a partir de 1592 al cabildo de Córdoba se le permitió elegir sus propios Alcaldes de la Santa Hermandad (Santillán Vélez, 1882a: 259, 296, 330). los indígenas "del servicio" -zona urbana- se aplicara la nueva regla "matrilo$\mathrm{cal}^{\prime}$, ya que con este sistema divergente se había generado "mucha quietud" entre los vecinos.

Al revisar detalladamente las peticiones enviadas por los cabildantes, evidenciamos la importante presencia de los Alcaldes de la Santa Hermandad en las sesiones analizadas. ${ }^{17}$ Estos Alcaldes eran funcionarios encargados de mantener el "orden" en espacio rural -o campaña-, desempeñándose como jueces de primera instancia en dicho espacio y aunque no tenían voz ni voto en el cabildo, muchas veces -según registramos para el caso de Córdoba- un mismo vecino se podía desempeñar al mismo tiempo como Alcalde Ordinario -con voz y voto- y Alcalde de la Santa Hermandad (Emiliani, 1994: 129-135; Piana, 1992: 225-226). ${ }^{18}$

Teniendo en cuenta lo anterior, podemos pensar que la importante presencia de Alcaldes de la Santa Hermandad en las sesiones en las que se le reclamó al gobernador la modificación de la regla "matrilocal" quizás evidencia los intereses que estos funcionarios estaban defendiendo. Es decir, dichos Alcaldes probablemente estuvieran preocupados porque la regla "matrilocal" no perjudicara los intereses de los vecinos con unidades productivas rurales, espacio en donde ellos desempeñaban sus funciones y en donde era más valorado el servicio indígena masculino.

La presión ejercida por los vecinos de Córdoba -y no sabemos si de otras jurisdicciones- sobre Mercado de Peñaloza lo llevó a establecer en 1597 una nueva ordenanza particular para esta ciudad, y luego otra general para todo el Tucumán. Sin embargo, antes de elaborar esta nueva normativa el gobernador participaría, junto a las principales autoridades religiosas, del Primer Sínodo del Obispado del Tucumán celebrado en Santiago del Estero en 1597, donde el matrimonio y la residencia indígena sería uno de los principales problemas abordados.

\section{El Primer Sínodo del Tucumán (1597)}

Los tres primeros Sínodos realizados en esta gobernación (1597, 1606 y 1607) serían organizados por el Obispo Fray Fernando de Trejo y Sanabria, segundo Obispo del Tucumán (1597-1614) y a quien se le atribuye el papel de primer organizador general de la diócesis (Bruno, 1967: 356-363). El Primer Sínodo fue llevado a cabo en 1597 y contó la con la participación de Mercado de Peñaloza, en carácter de gobernador y de consultor nombrado (Arancibia y Delaferrera, 1979: 93 y 133).

Tal como mencionamos, el Tucumán constituyó una región alejada del centro político y económico del Virreinato, fenómeno que también se plasmó en lo religioso siendo una Provincia donde la presencia de clérigos y sacerdotes fue escasa durante el periodo colonial temprano, generando que la evangelización de los indios quedara muchas veces en manos de los encomenderos (Piana, 1992: 232). La diócesis del Tucumán estuvo sujeta durante este periodo a la sede metropolitana de Lima y en este contexto las disposiciones de los primeros Sínodos siguieron los lineamientos generales establecidos en este espacio. A pesar de esto, a diferencia de la zona andina más influenciada por la tradición lascasiana que pondría un freno a la explotación indígena llevada a cabo en el marco de la encomienda, en estos años la iglesia del Tucumán no cuestionaría el sistema de encomiendas de "servicios personales" (Palomeque, 2000: 120; Crouzeilles, 2007). 
En relación a las medidas realizadas en torno al sacramento del matrimonio, en el análisis realizado J. M. Arancibia (1972) se evidencia la centralidad que tuvo el tema en los primeros Sínodos. Según afirma este autor, hubo dos asuntos en los que se desagregó el problema del casamientos: por un lado, la "libertad de los indios para contraer matrimonio" $\mathrm{y}$, por el otro, la "libertad de los indios para el uso del matrimonio y la vida conyugal" (Arancibia, 1972: 104-108).

En relación a la "libertad de los indios para contraer matrimonio", se legisló para frenar los llamados impedimentos matrimoniales y los casamientos forzados establecidos por los españoles, que entorpecían dicha libertad. En el Sínodo de 1597 se denunció que si bien casar por la fuerza a los indios o impedir el casamiento era un "gran mal", había muchos españoles "que cada día los hacen violentamente y los impiden". La solución instituida en este Sínodo fue castigar a los españoles que así obraran "dando por perdido el derecho que tuvieren de servirse de los indios o indias, a los cuales violentamente casaren o maliciosamente impidieran sus matrimonios", para lo cual contaron con el apoyo de Mercado de Peñaloza quien se comprometió a elaborar una ordenanza al respecto (Arancibia y Delaferrera, 1979: 152-153).

El otro asunto reglamentado, relacionado estrechamente al anterior, describe las causas que ocasionaban que los indígenas casados no hicieran vida conyugal. En la Constitución 14 del Primer Sínodo, denominada "Que duerman los indios casados con sus mujeres", se denunciaba que las mujeres "de servicio" dormían encerradas para que pudieran "vestirles y desnudarles" a las "encomenderas de indios" o esposas de los encomenderos. ${ }^{19}$

El breve examen realizado del Primer Sínodo, aunque no aporta demasiada información en torno a las reglas "patrilocales" o "matrilocales" de los matrimonios, permite observar cómo la reglamentación religiosa sobre este asunto, si bien siguió las líneas generales de los Concilios del espacio andino enfrentó problemas propios de un espacio de frontera, donde las autoridades coloniales y religiosas tuvieron menos capacidad -y a veces menos interés- para controlar los abusos o las decisiones de los vecinos encomenderos y sus esposas. La descripción de las situaciones registradas en las diferentes constituciones también nos permitieron observar algunas características específicas de este fenómeno, como, por ejemplo, las causas que podían hacer que los casamientos indígenas fueran impedidos o se realizaran de manera forzosa y las diferentes coacciones que evitaban la vida conyugal. ${ }^{20}$

\section{La ordenanza de Mercado de Peñaloza para Córdoba (1597)}

Luego de participar en el Primer Sínodo, Mercado de Peñaloza realizó un nuevo mandamiento para los matrimonios indígenas, específico para Córdoba, respondiendo a la presión ejercida por los grupos encomenderos de este espacio. Dicho mandamiento fue elaborado en diciembre de 1597 y ordenaba que:

[...] por quanto su señoría tenya echa ordenanza en rrazon de que las chinas que se casaren con yanaconas e yndios en esta gobernación lleven consigo a sus maridos por obiar algunas malicias que de lo contrario se solian rrecrecer como mas largamente se contiene en la dicha ordenanxa y aora por parte de los vezinos desta ciudad se le ha pedido declaración de la dicha ordenanza sobre si se a de entender con todas las yndias en general o en particular por tanto aprovando y rrevalidando la dicha hordenanza su señoria manda se entienda solamente con la chinas del servicio y casa de las personas cuyas fuere que las obiere doctrinado y enseñado a servir en qualquier manera y
19. En la Constitución 14 del Sínodo se ordenaba que: procuren los encomenderos y encomenderas de indios, que las indias hagan vida maridable con sus maridos, y no anden perdidas ni les den ocasión para ello [...] $Y$ asimismo les mandamos que no encierren a las chinas casadas para que duerman aparte de sus maridos, porque las han menester para que les sirvan en vestirles y desnudarles (Arancibia y Delaferrera, 1979:154). A su vez, en la Constitución 13 se puede corroborar que las mujeres españolas eran las principales responsables en impedir la vida conyugal y forzar casamientos de los indios para verse mejor servidas.

20. Otra de las causas importantes que el Sínodo señala como impedimento de la vida conyugal indígena eran los diversos "servicios" que los encomenderos hacían prestar a los hombres nativos, que los mantenían lejos de su hogar; entre ellos: el cultivo en lugares distantes de su residencia y los "trajines" o transportes (Arancibia y Delaferrera, 1979: 154). Aunque aquí nos referimos al Primer Sínodo realizado en 1597 , la denuncias y normativas instituidas por las autoridades religiosas también están registradas en el Segundo Sínodo (1606) y en el Tercer Sínodo (1607), ambos respaldados por el gobernador Alonso de Ribera (Arancibia y Delaferrera, 1979: 177-213). 
21. Según el Diccionario de Salvá ([1846] 2006) Chontal es el sitio poblado de chontas / Para América: el indio sin cultura y enseñanza. Es decir, que india "chontal" sería aquella en quien no se ha invertido en su “hispanización”.
22. En un trabajo previo, ya citado, dedicamos un capitulo a revisar diversas conceptualizaciones en torno las características del proceso de integración de los grupos indígenas al sistema colonial, y a definir el significado que en nuestra investigación adquirió el llamado proceso de "hispanización", al cual entendemos como, forzado o voluntario, de integración de las sociedades indígenas al sistema colonial sin que esto implique la mera recepción de elementos externos por parte de los grupos nativos ya que se parte de la idea de que las mismas tienen capacidad creativa (Borrastero, 2016: 150-167). no con las yndias chontales de los pueblos de los vezinos se guarde y cumpla (Santillán Vélez, 1882b: 51-52).

Con esta normativa el gobernador concedía a los vecinos el establecimiento de un sistema "divergente" de residencia para los matrimonios del espacio urbano y rural, permitiendo que en la zona urbana se utilizara la nueva regla "matrilocal", que implicaba que los hombres casados debían residir a donde vivían -y servían- las "chinas de servicio y casa de las personas que las obiere doctrinado y enseñado a servir", mientras que en los "pueblos de los vecinos" -pueblos de encomienda del espacio rural- se mantenía la regla "patrilocal", según la cual las "indias chontales" 21 casadas debían ir a residir -y servir- a los "pueblos" de sus maridos.

Según entendemos, la normativa "divergente" instituida para Córdoba dejaba conforme tanto a los vecinos que se beneficiaban con el nuevo sistema "matrilocal", como a los que preferían el "tradicional" sistema "patrilocal". Teniendo en cuenta esto, podemos pensar que el interés divergente de los vecinos quizás reflejó la finalidad de los encomendero por resguardar al miembro de la familia indígena sobre el cual habían invertido más tiempo y trabajo en "hispanizarlo"; es decir, en integrarlo, de manera forzosa o voluntaria, a las formas de trabajo predominantes en los diferentes espacios productivos. Retomaremos la reflexión sobre este asunto en las consideraciones finales. ${ }^{22}$

Entendemos que el mandamiento establecido por Mercado de Peñaloza para Córdoba refleja no sólo la concreción legal de una regla "divergente" para el espacio urbano y rural, acorde a los intereses productivos de los diferentes grupos de vecinos encomenderos, sino que también evidencia la capacidad de dichos encomenderos -congregados en el cabildo- para modificar una normativa que regulaba los matrimonios indígenas de toda la gobernación.

\section{La ordenanza de Mercado de Peñaloza para la gobernación del Tucumán (1598)}

La última legislación registrada en las Actas Capitulares, dentro del intercambio normativo reseñado, fue realizada por Mercado de Peñaloza para todo el Tucumán en 1598, siendo pregonada en Córdoba en agosto de ese año. Mediante esta ordenanza el gobernador dejaría sin vigencia las medidas previamente adoptadas para Córdoba, retornando a la legislación general existente en el momento previo a su gestión. En esta legislación afirmaba:

[...] queriendo su señoria poner rremedio y que se escussaren pleytos, devates y diferensias y enemistades y ynquietudes que cada dia habia entre los dichos vezinos - estando en santiago del estero cavesa desta governación en dos días del mes de mayo del año de mil quinientos y noventa y cinco su señoria proveyo un auto y hordenanza en que mando que atento a lo dicho alli en adelante las yndias [los indios] que se casen con chinas y yndias del servicio y casa de otros amos fuese a servir al amo de tal china lo qual aviendo se pregonado se cumplio y a cumplido hasta oy - y agora su señoria estando informado y le consta que muchos yndios estan mucho tiempo amancebados con yndias de otros vezinos y con temor de que si se casan hande yr a serbir al amo de su mujer y no an de servir al suyo donde son bien tratados y tienen su natural no se osan ni quieren cassar sino estando como se estan amancevados en pecado mortal de lo qual la divina majestad es ofendida y como caussa principal combiene escusarlo y poner en ello remedio - Por tanto mandava y mando que quedando en su fuerza y vigor todo lo que en virtud de la dicha 
ordenanza hasta oy sea hecho - de aqui en adelante los yndios y yanaconas que se casaren lleven consigo a sus mugeres y el amo de ese yndio se sirva de la yndia que se casare no embargante que la tal yndia labrandera china cocinera de otro amo lo qual asi se guarde y cumpla de aqui en adelante y las justicias mayor y hordinarias de toda esta gobernación asi lo manden guardar y cumplir cada uno en su jurisdicción (Santillán Vélez, 1882b: 103-104).

Esta normativa, de la que citamos solo un fragmento, se refiere a los conflictos entre los vecinos que motivaron a que el gobernador estableciera en 1595 un sistema "matrilocal" para los matrimonios y los problemas que este mandamiento ocasionó, lo cual conduciría en última instancia a restablecer en 1598 la anterior regla "patrilocal".

Si bien en las Actas revisadas no encontramos más referencias a este asunto, en otros documentos posteriores pudimos constatar cómo las denuncias y los debates en torno la forma que debían tener los casamientos y la residencia indígena continuaron más allá del periodo analizado. Esto nos lleva a suponer que la regla "patrilocal" generalizada en el Tucumán siguió sin satisfacer a los diferentes actores de este espacio, y que al mismo tiempo los abusos realizados por los encomenderos sobre los matrimonios indígenas continuaron. ${ }^{23}$

\section{Consideraciones finales}

A lo largo de este artículo fuimos profundizamos en el análisis de las normativas en torno a los matrimonios y la residencia indígena en la jurisdicción de Córdoba -como parte de la gobernación del Tucumán- entre 1573 y 1598, tema sobre el cual ya habíamos realizado algunos avances previos (Borrastero, 2016).

En la primera parte analizamos el contexto normativo general -previo a las ordenanzas de Abreu de 1576-, centrándonos en las legislaciones establecidas por Toledo en 1570 para el virreinato del Perú. Este Virrey, instauraría un sistema de explotación y de organización para las poblaciones nativas de los Andes centrales, que consolidaría el poder del Estado Colonial y al mismo tiempo transformaría las formas de vida que tenían las poblaciones indígenas de este espacio. El orden regulado por Toledo, que normativizaba un sistema de reducciones, el tributo, las formas de gobiernos, la evangelización, etc., pondría fin al proyecto señorial que buscaban imponer los grupos encomenderos, cortando la relación directa que existía entre estos últimos y los indígenas encomendados. En relación al tema aquí analizado, observamos que tanto las ordenanzas de Toledo como las disposiciones realizadas por el Tercer Concilio Límense -que siguieron los lineamientos principales del Concilio de Trento- fijaron la residencia de la familia indígena en el lugar de pertenencia del hombre -esposo/padre; es decir, reglamentaron un sistema "patrilocal" para los matrimonios.

Este contexto normativo previo nos permitió observar las diferencias existentes entre la zona central del Perú y espacios marginales del virreinato, como era la gobernación del Tucumán. En esta gobernación, las políticas establecidas por las autoridades españolas difícilmente llegaron a aplicarse durante el periodo colonial temprano, debido al gran poder de decisión que durante largo proceso de conquista "privada" y colonización adquirieron los grupos encomenderos.

Según mencionamos, la población indígena de este espacio -al igual que la de otras jurisdicciones con características similares- quedaría sometida al sistema
23. A medida que elaboramos este artículo, fuimos localizando varios documentos posteriores al periodo indagado. Dos de ellos nos permiten ejemplificar cómo continuaron las normativas y denuncias en torno al fenómeno analizado. En primer lugar, las ordenanzas realizadas por el Oidor Francisco de Alfaro (16101611), donde se confirma la regla “patrilocal”. En la Ordenanza 43 se afirma que: "la yndia casada de qualquier pueblo aya de yr y vaya a bivir en el pueblo de su marido lo qual se entienda y practique (...) y ansi las mugeres casadas an de estar en el pueblo de sus maridos sin escusa alguna aunque digan que el marido esta uydo mucho tiempo a y que no sabe del" [...] (Levillier, 1918: 309) Y en segundo lugar el Parecer del Padre Jesuita Juan Romero (1608), ilustrando los abusos que los vecinos de Córdoba siguieron realizando sobre los indígenas casados; en este documento se afirma que: "En Córdoba y en toda la gobernación, por sacar muchas chinas para sus casas y labrados las señoras de indios, y por sacar la gente más moza, quedan los pueblos sin mujeres para que se casen los indios. Y, para tener más segura las que sacan para chinas, las casan muy de ordinario contra su voluntad con cualquiera que tenga la forma de hombre o viejo y ansí no se juntan y amanceban y viven muriendo. En toda la gobernación es mal que cunde mucho el impedir los matrimonios, porque queriéndoseles una india casar con indio que sirva a otro vecino, o la echan en prisiones o la llevan a pueblos, y lo menos es amenazalla y azotaIla y aun trasquilalla. $Y$ hay muchas personas que por esta causa ni las dejan salir a misa ni sermón ni ver el sol" [...] en Archivo General de Indias colección escritos. Colección de copias de documentos del Archivo General de Indias. Tomo 185, Doc. 3887, fs. 13-21. 
24. Recuperando la perspectiva propuesta por Doucet (1990), entendemos que las normativas aquí analizadas quizás pueden ser leídas como "testimonios" -indirectos- de lo que podía estar sucediendo en la práctica en relación a los matrimonios y la residencia indígena. de encomiendas de "servicios personales", que sería "legalizado" con las ordenanzas de Abreu de 1576. Estas legislaciones no fijarían una "tasa" en producto o dinero ni separarían al pueblo de indios del encomendero, como en el resto del virreinato, sino que al contrario autorizaría a los encomenderos a mantener a los indios como sus vasallos; es decir, a mantener "sujeta bajo su jurisdicción" a toda la familia sobre la cual se instauraría un "dominio" sin control estatal.

Luego, para comprender mejor la especificidad de la normativa analizada, reseñamos sintéticamente las características que adquirieron las relaciones establecidas entre los grupos indígenas y españoles en la jurisdicción de Córdoba durante el periodo colonial temprano. Aquí explicamos los diferentes oficios llevados a cabo por las familias indígenas que habían sido trasladadas al espacio urbano -principalmente desde noroeste de la jurisdicción- por los españoles, y la divergente valoración realizada por estos últimos del servicio femenino y masculino. En relación a este asunto, mostramos cómo en el espacio urbano los encomenderos -y sus esposas- valoraron especialmente los trabajos llevados a cabo por las mujeres nativas -dedicadas entre otras cosas a la elaboración de finos oficios textiles-, mientras que en el espacio rural fue más apreciado el servicio indígena masculino -cuyos trabajos aparentemente tenían menos movilidad que los de sus pares en el espacio urbano.

En la segunda parte del artículo, recuperamos la perspectiva metodológica propuesta por Doucet ${ }^{24}$ y revisamos las ordenanzas de Abreu de 1579 que reglamentaron un sistema "patrilocal" para los matrimonios indígenas de Córdoba, en consonancia con las reglas generales instituidas para el virreinato del Perú. Estas normativas serían modificadas en 1595 por Mercado de Peñaloza, quien implementaría un novedoso sistema "matrilocal" para toda la gobernación, considerando el alto valor que tenían para determinados encomenderos -no sabemos si para todos o algún grupo específico dentro del Tucumán- las mujeres indígenas y los daños que había ocasionado el anterior sistema "patrilocal". Apenas instaurada esta nueva reglamentación, los vecinos de Córdoba presionarían a Mercado de Peñaloza para que modificara la misma y estableciera un nuevo sistema "divergente" para los casamientos, "matrilocal" en el espacio urbano y "patrilocal" en el espacio rural. Según planteamos, es posible que esta normativa divergente estuviera beneficiando a grupos de encomenderos con intereses económicos diferentes dentro de la jurisdicción de Córdoba.

Frente a esta solicitud, y luego de participar en el Sínodo de 1597, el gobernador reglamentaría el sistema "divergente" solicitado por los vecinos de Córdoba. Esta medida nos llevó a reflexionar, por un lado, sobre el gran poder de los encomenderos de este espacio para modificar una normativa vigente para toda la gobernación e imponer una nueva legislación elaborada en función de sus preferencias productivas y, por otro lado, a observar el nivel de control que dichos encomenderos y sus esposas tenían sobre las pautas de comportamiento y evangelización de los grupos indígenas que estaban bajo sus dominio, fenómeno también evidenciado en las disposiciones establecidas en el Primer Sínodo del Tucumán. Finalmente, en 1598 Mercado de Peñaloza restablecería la anterior regla "patrilocal" para toda la gobernación, legislación que sería confirmada luego por el Oidor Alfaro (1610-1611).

La lectura comparativa de las Actas Capitulares y otros documentos contemporáneos, entre ellos las normativas generales proveniente de las autoridades civiles y religiosas y otras fuentes previamente revisadas, como la visita de 1598, nos permitió complejizar nuestra reflexión sobre las normativas en 
torno a los casamientos indígenas, observando los diferentes intereses y las contradicciones existentes entre diversos actores que, en un contexto en cual aún no se había consolidado el dominio colonial, estaban buscando definir y/o estructurar la forma que debían tener las familias indígenas sometidas al sistema de encomienda de "servicio personales".

Finalmente, entendemos que al estructurar determinadas "formas" para las familias indígenas, los grupos encomenderos probablemente ejercieron un control mayor sobre el miembro más valorado o "hispanizado" de las unidades familiares indígenas. ${ }^{25} \mathrm{~A}$ su vez, consideramos que este proceso de "hispanización" estuvo determinado tanto por la inversión de tiempo y trabajo realizada por los encomenderos sobre los indígenas, como por la participación activa estos últimos en las actividades productivas organizadas o incentivadas por los colonos españoles.

\section{Agradecimientos}

Agradecemos los sugerentes comentarios de Laura Quiroga a la ponencia presentada en las XVI Jornadas Interescuelas/ Departamentos de Historia con sede en Mar del Plata el 08/2017; también fueron muy útiles las preguntas y comentarios realizados por Silvia Palomeque, Isabel Castro Olañeta y Roxana Boixadós en el marco de las mismas jornadas. Por último fueron provechosos los comentarios realizados por los revisores anónimos sobre este trabajo.
25. La revisión realizada hasta el momento no nos permite pensar que se tratara de unidades domésticas, en términos antropológicos, ya que los documentos consultados solo nos han permitido ver la superficie de las relaciones establecidas entre los grupos indígenas y españoles.

14. La Ord. 37 menciona que "por quanto algunos vezinos se les an quedado yndios en el Piru los quales an dejado a sus mugeres aca e hijos e por falta de los padres padecen necesidad e no tiene quien les ayuden a hazer sus chacaras con que se sustentan", a partir de la cual podemos observar una de las posibles causas que separaban a los matrimonios: los indios varones eran enviados por sus encomenderos a lugares lejanos, quedando las mujeres/esposas y/o los hijos del matrimonio separados del padre/esposo (Leviller, 1920b: $40 \mathrm{y}$ 43). (En página 38).

15. jurisdicción de Córdoba han sido mencionadas en investigaciones anteriores (Molina, 1952; Piana, 1992), no se ha indagado específicamente sobre estas reglamentaciones. Molina (1952) es el primero en publicar las ordenanzas de Abreu para Córdoba, confundiendo las normativas de 1576 con las 1579 y considerando a estas últimas como las "ordenanzas que regían para todo el Tucumán” (Molina, 1952: 196 y 211-212). En nuestro análisis hemos utilizado la transcripción dirigida por Luque Colombres, que es la versión más completa y clara con la que contamos (Acta del día 23/05/1579, "pregonada" públicamente el 25/05/1579. Luque Colombres, 1974: 298-301). (En página 38). 


\section{Fuentes consultadas}

" Arancibia, J. M. y N. C. Dellaferrera (1979). Los sínodos del antiguo Tucumán celebrados por fray Fernando de Trejo y Sanabria, 1597, 1606, 1607. Facultad de Teología. Universidad Católica Argentina. Buenos Aires, Editora Patria Grande.

" Archivo General de Indias colección escritos (1912-1917). Colección de copias de documentos del Archivo General de Indias (1598-1608). Tomo 185, Doc. 3887, fs. 13-21. Buenos Aires, Biblioteca Nacional Mariano Moreno. (Colección Gaspar García Vi as).

» Levillier, R. (1918). Carta del licenciado Don Francisco de Alfaro. Tucumán, 23-l-1612 en Correspondencia de la ciudad de Buenos Ayres con los Reyes de España 1615-1635 II. Madrid, Imprenta de Juan Pueyo.

» Levillier, R. (1920a). Gobernación del Tucumán: Papeles de gobernadores en el siglo XVI. Documentos del Archivo de Indias: II Parte. Madrid, Imprenta de Juan Pueyo.

" Levillier, R. (1920b). Ordenanzas dadas por Gonzalo de Abreu para el buen tratamiento de los indios en las provincias del Tucumán y estableciendo reglas para su trabajo en el laboreo de las minas. Santiago del Estero, 10-IV-1576 en Gobernación del Tucumán: Papeles de gobernadores en el siglo XVI. Documentos del Archivo de Indias. II Parte. 32-45 Madrid, Imprenta de Juan Pueyo.

" Luque Colombres, C. (1974) (Director) Actas Capitulares de la Ciudad de Córdoba I. Córdoba, Archivo Municipal de Córdoba.

»Molina, R. A. (1952). El estatuto del trabajador argentino durante la dominación hispánica en Primer Congreso de Historia de los Pueblos de la Provincia de Buenos Aires, II, La Plata.

»Piana, J. (1987). Visita a los indios de servicio de la ciudad de Córdoba del Tucumán en 1598. Historiografía y Bibliografía Americanista XXXI (1): 27-61.

»Santillán Vélez, L. (Director) (1880). Actas Capitulares de Córdoba I [1573-1587]. Córdoba, Municipalidad de Córdoba/ Establecimiento tipográfico de "La Carcajada".

»Santillán Vélez, L. (1882a). Actas Capitulares de Córdoba. II [1588-1597]. Córdoba, Municipalidad de Córdoba/ Establecimiento tipográfico "Eco de Córdoba”.

"Santillán Vélez, L. (1882b) Actas Capitulares de Córdoba. III [1597-1603]. Córdoba, Municipalidad de Córdoba/ Establecimiento tipográfico "Eco de Córdoba".

"Salvá, V. ([1846] 2006). Nuevo diccionario de la lengua castellana, que comprende la última edición íntegra, muy rectificada y mejorada del publicado por la Academia Española, y unas veinte y seis mil voces, acepciones, frases y locuciones, entre ellas muchas americanas [...]. Disponible en Internet: http://www.cervantesvirtual.com/nd/ark:/59851/bmcmw2c3. Consultado el: 4 de abril de 2018.

"Sarabia Viejo, M. J. (1989). Francisco de Toledo. Disposiciones Gubernativas para el virreinato del Perú 1575-1580, I. Sevilla, Publicación de la Escuela de Estudios Hispano-Americanos de Sevilla. 


\section{Q Bibliografía}

"Arancibia, J. M. (1972). El matrimonio en los sínodos del obispo Trejo. Teología: Revista de la Facultad de Teología de la Pontificia Universidad Católica Argentina 21: 93-110.

»Arnold, D. (comp.) (1998). Gente de carne y hueso. Las tramas de parentesco en los Andes. La Paz, CIASE/ ILCA.

»Assadourian, C. S. (1972). "La conquista” en Assadourian, C. S.; Beato, G. Y. y J. C. Chiaramonte (comps.), Historia argentina. De la conquista a la independencia: 13-114. Buenos Aires, Paidós.

"Assadourian, C. S. ([1968] 1982). “Economías regionales y mercado interno colonial: el caso de Córdoba en los siglos XVI y XVII" en Assadourian, C. S., El sistema de la economía colonial. 18-56, Lima, Instituto de Estudios Peruanos.

"Assadourian, C. S. (1994). "Los señores étnicos y los corregidores de indios en la conformación del estado colonial” en Assadourian, C. S., Transiciones hacia el sistema colonial andino: 209-279. Lima, El Colegio de México/ Instituto de Estudios Peruanos.

»Arellano I. y J. M Usuñariz (eds.) (2005). El Matrimonio en Europa y el mundo hispánico. Siglo XVI y XVII. Madrid, Visor Libros. Madrid.

"Borrastero, L. (2015) Las sociedades y su incorporación al proceso de producción de textiles en el período colonial temprano (Córdoba, 1573-1620). Estudios del ISHIR 5 (12): 54-81, Investigaciones Socio Históricas Regionales, Unidad Ejecutora en Red - CONICET. Disponible en Internet: http://revista.ishir-conicet.gov.ar/ojs/index.php/revistalSHIR/ issue/view/56. Consultado el: 30 de abril de 2018.

" Borrastero, L. (2016). "Las sociedades indígenas y su participación en la economía mercantil durante el período colonial temprano. ¿Un proceso de ‘hispanización’? (Córdoba 1573-1620)”. Trabajo Final de Licenciatura en Historia, FFyH-UNC. Córdoba. (Ms.)

»Bruno, C. (1967). Historia de la iglesia en la argentina. 1600-1632, II. Buenos Aires, Editorial Don Bosco.

" Carmignani, L. (2013). “Los "partidos” de la jurisdicción de Córdoba, las sociedades indígenas y la percepción del espacio. Gobernación del Tucumán, principios del Siglo XVII" en Rocchetti, A. M.; Yedro, M. y E. Olmedo (comps.), Arqueología y Etnohistoria del Centro-Oeste Argentino: 159-172. Río Cuarto, Córdoba, UniRio editora.

"Castro Olañeta, I. (2006). Transformaciones y continuidades de sociedades indígenas en el sistema colonial. El pueblo de indios de Quilino a principios del siglo XVII. Córdoba, Alción Editora.

"Crouzeilles, C. (2007). "Religiosos y sociedad colonial. Los religiosos, su ingreso al Tucumán y su incidencia política en el sistema de explotación económico sobre la sociedad indígena (Tucumán, 1535-1615)". Trabajo Final de Licenciatura en Historia. Córdoba, Escuela de Historia, Facultad de Filosofía y Humanidades - Universidad Nacional de Córdoba, Córdoba. (Ms.)

》Doucet, G. G. (1986). Los réditos de Quilpo: funcionamiento de una encomienda cordobesa a fines del siglo XVI. Jahrbuch für Geschichte Lateinamerikas 23: 63-119.

"Doucet, G. G. (1990). “La encomienda de servicio personal en el Tucumán, bajo régimen legal: comentarios a las Ordenanzas de Gonzalo de Abreu" en Levaggi, A. (coord.), El Aborigen y el Derecho en el Pasado y el Presente: 141-244. Buenos Aires, Universidad del Museo Social Argentino. 
»Emiliani, J. R. (1994). Manual de Administración indiana. Córdoba, Copyright.

» Imolesi, M. E. (2012). Teoría y práctica de la cristianización del matrimonio en Hispanoamérica colonial. Buenos Aires, Instituto de Historia Argentina y Americana “Dr. Emilio Ravignani”, Universidad de Buenos Aires. (Serie Las Tesis del Ravignani).

» Jara, Á. ([1961] 1981). Guerra y sociedad en Chile. Santiago de Chile, Editorial Universitaria.

»Laguens, A. y M. Bonnin (2009). Sociedades indígenas de las sierras centrales. Arqueología de Córdoba y San Luis. Córdoba, Universidad Nacional de Córdoba.

» Latasa, P. (2005). “La celebración del matrimonio en el virreinato: disposiciones en la arquidiócesis de Charcas y Lima (1570-1613) en Arellano, I y J. M. Usuñariz (eds.), El Matrimonio en Europa y el mundo hispánico. Siglo XVI y XVII: 237-256. Madrid, Visor Libros.

» López Lamerain, C. (2011). El III Concilio de Lima y la conformación de una normativa evangelizadora para la provincia eclesiástica del Perú. Intus Legere Historia 5 (2): 51-68. Chile, Universidad Adolfo Ibáñez.

» Lorandi, A. M. (1988). El servicio personal como agente de desestructuración del Tucumán colonial. Revista Andina 6: 135-173.

» Mayer E. y R. Bolton (comps.) (1980). Parentesco y matrimonio en los Andes. Lima, Pontificia Universidad Católica del Perú, Fondo Editorial.

»Palomeque, S. (2000). “El mundo indígena. Siglos XVI-XVIII” en Tandeter, E. (dir.), Nueva Historia Argentina. La sociedad colonial II: 87-144. Buenos Aires, Ed. Sudamericana.

» Piana, J. (1992). Los indígenas de Córdoba bajo el régimen colonial 1570-1620. Córdoba, Dirección General de Publicaciones de la Universidad Nacional de Córdoba.

» Rípodas Ardanaz, D. (1977). El Matrimonio en Indias. Realidad social y regulación jurídica. Buenos Aires, Fundación para la educación, la ciencia y la cultura. 